\title{
The 13th World Conference on Titanium (Ti-2015)
}

\author{
M. ASHRAF IMAM ${ }^{1,2}$ \\ 1.--Department of Mechanical and Aerospace Engineering, School of Engineering and Applied \\ Science, George Washington University, 725 23rd Street, N.W., Tompkins Hall, Suite 105B, \\ Washington, DC 20052, USA. 2.—e-mail: ashrafimam@gwu.edu
}

\section{INTRODUCTION}

Among the structural materials developed in the twentieth century, titanium and its alloys play a leading role. Initially, the main focus was on titanium's high specific strength, including that at elevated temperature. This led to wide use in the aircraft and space industries. Later, attention was paid not only to high specific strength but also to excellent fatigue resistance, strong spring-back characteristics, high-temperature performance, corrosion resistance, and biocompatibility. Titanium emerged as a "wonder" metal that makes sense as the material of choice for a wide variety of applications, including jewelry, bicycle frames, missiles, airplanes, helicopters, submarines, automobile, bone implants and surgical instruments.

To assess the development of titanium worldwide, the International Conference on Titanium was first held in May 1968, and has convened every 4 years (3 years for one conference after 1992) as a recurring conference ever since.

\section{THE 13TH WORLD CONFERENCE}

The most recent, 13th World Conference, was hosted by The Minerals, Metals \& Materials Society of the USA in San Diego, California, 16-20 August, 2015, at the Manchester Grand Hyatt, San Diego.

The 13th World Conference was co-sponsored by: the Non-ferrous Metals Society (NFsoc), China; the Institute of Materials, Minerals and Mining (IOM), of the United Kingdom; Interstate Association Titan, Commonwealth of Independent States (CIS); Deutsche Gesellschaft für Materialkunde

The International Conference on Titanium was begun in 1968 to assess the national significance attached to the development of titanium in relation to the technical needs of the countries participating in this conference. The conference, held every 4 years, attracts strong international participation. This article reviews the 13th World Conference on Titanium, hosted by The Minerals, Metals \& Materials Society of USA and held in San Diego, California, USA, 16-20 August, 2015.
(DGM), of Germany; Japan Institute of Metals (JIM) of Japan; and the Société Française de Métallurgie et de Matériaux (SF2M) of France.

The International Organizing Committee members from different countries representing their organizations are: Vasisht Venkatesh and Rodney Boyer, United States; Martin Jackson, United Kingdom; Orest Ivasishin, CIS; Mitsuo Niinomi, Japan; Lothar Wagner, Germany; Patrick Villechaise, France; Hui Chang, China.

National Organizing Committee members were: Vasisht Venkatesh (Chair), Pratt \& Whitney; Julie Christodoulou (Vice-Chair), U.S. Office of Naval Research; John Allison, University of Michigan; Sreeramamurthy Ankem, University of Maryland; Rodney Boyer, RBTi Consulting; Amit Chatterjee, Rolls-Royce; Hamish Fraser, The Ohio State University; M. Ashraf Imam, The George Washington University; Yoji Kosaka, TIMET; Adam Pilchak, U.S. Air Force Research Laboratory; Henry Rack, Clemson University; and Andy Woodfield, GE Aviation.

\section{PARTICIPATION AND PRESENTATIONS AT THE CONFERENCE}

The conference attracted participants from more than 25 countries. The total number of presentations exceeded 385 including more than 360 oral presentations and approximately 23 poster presentations. Details of attendees are presented in Fig. 1.

There were many excellent presentations from different countries that will be published in the conference proceedings. Because it would be difficult to present highlights of all the presentations in this short article, the focus is on the plenary talks from the organizing committee member countries.

\section{TITANIUM RESEARCH DEVELOPMENTS IN THE UNITED KINGDOM}

"Titanium Research Developments in the United Kingdom" was authored by Martin Jackson of the University of Sheffield and Matthew Thomas of 


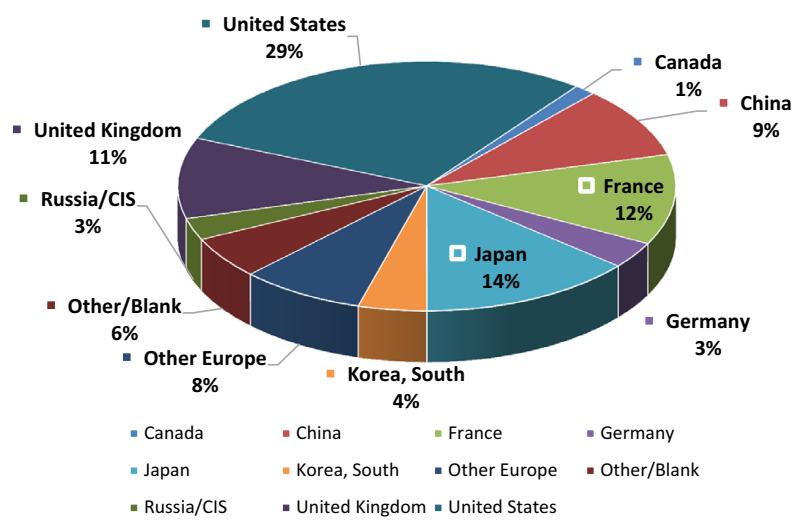

Fig. 1. Percentage of Attendees by countries.

TIMET UK and presented by Martin Jackson. The use of Ti by the UK industry continues to increase in line with world trends, as does the level of research activity on $\mathrm{Ti}$ in UK universities. He described some of the UK titanium alloy research developments since the last World $\mathrm{Ti}$ Conference in 2011. The current research and industry landscape were presented, introducing the key industry sponsors and university expertise. In addition, the increasing role that new High Value Manufacturing Catapult centers are contributing to accelerating university ideas into industry, were demonstrated through case studies. The presentation underlined the increasingly strong and collaborative fundamental research conducted at UK universities, and the role of advanced characterization and modeling techniques in order to better understand the effects of loading and environment on titanium alloys. In the UK today there is a vibrant, collaborative $\mathrm{Ti}$ research community in both industry and academia, working together on a range of topics from alternative extraction and powder processing methods to rapid manufacturing, joining and near-net shape technologies.

It is interesting to note that the UK government announced plans to fund a $£ 235$ million to Sir Henry Royce Institute for Advanced Materials at The University of Manchester, complemented by satellite centers at Leeds, Liverpool and Sheffield, in order to create, according to the UK Chancellor of the Exchequer: a "Northern Powerhouse" of scientific innovation and training. The specific scope was being determined, but the institute is likely to have a significant $\mathrm{Ti}$ alloy processing research activity.

There have been many examples of accelerated $\mathrm{Ti}$ lower-cost manufacturing routes and new components from universities to industry, through the High Value Manufacturing (HVM) Catapult centers. The center, backed by $£ 200$ million government funding, has a strategic aim to revitalize UK manufacturing, providing a gateway for UK business to access the best talent and facilities. For example, Rolls-Royce used the center to 3D print a Trent XWB-97 front bearing housing.

Advances in understanding of the fundamentals of $\mathrm{Ti}$ alloys are predominantly driven by RollsRoyce. Since Ti-2011, EPSRC/Rolls-Royce sponsored researchers at UK universities have used advanced characterization techniques, such as synchrotron $\mathrm{x}$ ray, neutron diffraction and atomic force spectroscopy, in addition to higher resolution electron microscopy and micromechanical testing, to provide the aerospace community with a greater understanding of topics, such as deformation modes during loading, crack propagation, dwell sensitivity and demanding environments of safety-critical aero-engine $\mathrm{Ti}$ alloy components. In all cases, research in this area has been conducted on TIMET material and a significant amount of fundamental research is co-sponsored by TIMET. This also includes TIMET's continuing alloy development program. Over recent years, this program has produced a number of candidate alloys for advanced applications. In order to provide the fundamental basis to assist with alloy development and performance optimization, TIMET have work closely with the UK universities of Manchester, Sheffield and Swansea.

Metalysis have continued their development of their solid-state extraction process (formerly known as the FFC process) and have received major investment from the Australian mining company Iluka, which is investing in the conversion of synthetic rutile directly to novel $\mathrm{Ti}$ alloys. In 2013, they received attention in the UK national press when a component was 3D printed from their powder (see Fig. 2), and Jaguar Land Rover were quoted as saying, "If a new process was capable of reducing the overall cost of titanium products by such a large amount, then many industries, including automotive, might be interested". An exciting

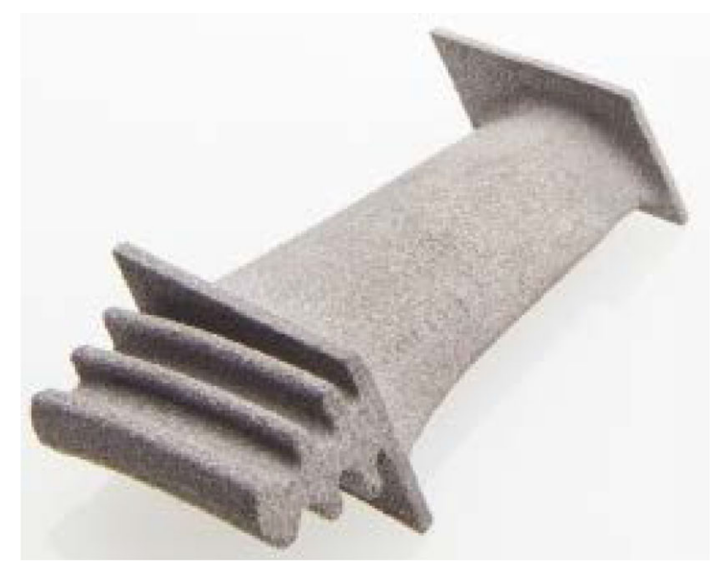

Fig. 2. A 3D-printed turbine blade fabricated using selective laser sintering at The University of Sheffield using Metalysis spherical powder. 
development since the investment is the demonstration that low-oxygen $\mathrm{Ti}$ alloys can be produced directly from synthetic rutile, and such material has been processed through conventional and novel consolidation routes. In summary, Metalysis powders have been successfully used for near-net shaping and bulk processing and could provide an alternative $\mathrm{Ti}$ source within the next decade.

There have been significant global takeovers that will have an impact on Ti research in the UK. RTi International acquired Aeromet International and Osborne Steel Extrusions in 2011 and 2013, respectively. Then, in 2015, RTi was acquired by Alcoa to increase their value add-on portfolio for the $\mathrm{Ti} /$ aerospace market. In 2014, Alcoa further increased their aerospace component footprint by acquiring Firth Rixson, which has metal manufacturing sites around Sheffield in the UK. It has also been well documented that Precision Cast Corporation (PCC) bought TIMET, and, with Wyman Gordon already part of their group, the UK Ti primary processing supply chain could be dominated by the US manufacturing giants, Alcoa and PCC, in years to come.

\section{RECENT ADVANCES IN TITANIUM TECHNOLOGY IN THE USA}

"Recent Advances in Titanium Technology in the USA" was authored by Vasisht Venkatesh (from Pratt \& Whitney) and Rodney R. Boyer (retired from Boeing) and presented by Vasisht Venkatesh. Titanium production in the USA has been rising steadily, driven by increased aircraft production rates to meet the demand for next generation airframes and engines for the next decade. Air traffic growth in emerging markets around the world, along with legacy fleet upgrades to meet new fuel efficiency standards and cost pressures, has resulted in large orders for new aircraft. Good compatibility between titanium and carbon fiber composites has led to a growing rate of the increased use of titanium in new airframe structures utilizing higher composites usage.

It is evident that wider use of titanium and its alloys is limited by the high cost associated with the high energy requirements to refine sponge from $\mathrm{TiO}_{2}$. Conventional commercial methods, such as the Kroll process, are batch processes that have significant energy, labor and material costs that contribute to the high price of titanium. The advanced research projects agency-energy (ARPAE) of the Department of Energy (DOE) has funded a program called the modern electrochemical advances in light metal systems (METALS) to find cost- and energy-effective solutions to process and recycle metals for light-weight vehicles and aircraft. A number of projects led by universities and industries are currently underway to simplify titanium production compared to conventional extraction and conversion processes:
1. Direct Production of Titanium Powder SRI International is developing a reactor that is able to either convert titanium tetrachloride or multiple metal chlorides to titanium alloy powder in a single step.

2. Direct Titanium Production from Titanium Slag The University of Utah's reactor utilizes a magnesium hydride solution as a reducing agent to break less-expensive titanium ore in a single step.

3. Segmented Cell for Electrowinning Titanium Case Western Reserve University is developing an electrochemical cell that produces titanium from titanium salts using a series of layered membranes.

4. Advanced Electrowinning of Titanium The iMetalx Group is developing a new electrochemical titanium production process that avoids the cyclical formation of undesired titanium ions.

5. Advanced Electrowinning of Titanium The Materials \& Electrochemical Research (MER) Corporation is developing a new electrochemical titanium production process that avoids the cyclical formation of undesired titanium ions, thus significantly increasing the electrical current efficiency.

6. Electrochemical Cell for Advanced Titanium Production The Titanium Metals Corporation (TIMET) is developing an electrochemical process for producing pure high-quality titanium powder.

While the aerospace sector continues to account for over $70 \%$ of the titanium produced, efforts are underway to maintain and grow titanium's presence through developing new processes to lower manufacturing cost, enhancing the performance of existing and new titanium alloys to meet requirements of new applications and developing computational materials models to reduce new alloy development cycle times and/or acceleration of introduction of new process qualification times. The development and qualification of a 3rd generation forgeable $\gamma$ TiAl for low-pressure turbine blades in the Pratt \& Whitney PW1000G engine is an example of enhanced titanium alloy capability. Similarly, new $\alpha+\beta$ alloys such as TIMETAL ${ }^{\circledR} 54 \mathrm{M}$ and ATI $425^{\circledR}$ are being evaluated for superplastically formed nacelle components in next generation airframes and engines. Another example is the successful application of "Integrated Computational Materials Modeling (ICME)" to rapidly design and qualify new alloys, as demonstrated by QuesTek, which has developed and implemented Ferrium M54 alloy for the United States Navy's T-45 hook shank landing gear. More recently, QuesTek has used ICME tools and methods to design and develop three new castable titanium alloys that would reduce costs by lowering vanadium levels and by increased tolerance to impurities, i.e., increased use of scrap. 
These alloys exhibit excellent processability to achieve better strength and ductility than cast Ti$6 \mathrm{Al}-4 \mathrm{~V}$.

\section{TITANIUM PRODUCTION, RESEARCH AND APPLICATIONS IN CIS: CURRENT STATUS AND FUTURE TRENDS}

"Titanium Production, Research and Applications in CIS: Current Status and Future Trends" was authored by Orest M. Ivasishin from CIS, Interstate Association Titan and Andrey V. Aleksandrov from the Institute for Metal Physics and was presented by Orest Ivasishin. He gave an overview of recent activities of titanium in CIS including production, application, new research, and developmental studies at universities and research institutions. Since the last World Titanium Conference in 2011, the CIS titanium industry remains an important contributor to the global titanium market by both volume and applications. Export shipments of titanium, especially mill products, prevail above domestic ones which remain relatively low, despite some progress in the scale of using titanium in the CIS end-users such as the aerospace, chemical and marine (shipbuilding) industries. Titanium research activity is developing in line with industry needs and is motivated by both performance-driven and cost-driven applications. In many cases, studies are being stimulated by Interstate Association Titan through broad cooperation within CIS. Due to the application-oriented nature of research activities, fundamental studies on the complex nature of titanium-based materials are gradually shifting to applied research to develop and scale-up advanced alloys, processes and new applications. Despite the very complicated political and economic situation within CIS, representatives of the titanium industry and science are putting significant efforts into maintaining strong links between participants of the formerly united structure.

In CIS, like in the rest of the titanium world, after a significant reduction in the titanium output through all the titanium processing, including elaboration, extraction, melting and mill production in 2008-2009 caused by world economic crisis, a recovery in titanium activity was observed in 2010-2011. Although the capacity of titanium producers did not notably increase, the existing facilities have been working near their capacity. Main efforts have been focused on looking for new markets. Some investments were carried out to develop new products in order to be in line with customer requirements.

Three of six sponge-producing countries belong to CIS. There are currently four sponge producers in the CIS: two in Russia, one in Kazakhstan and one in Ukraine. Their combined capacity of slightly above $90 \mathrm{kT}$ per year remained practically unchanged during the last 4-year period. The CIS share in the global sponge production capacity now consists of about $27 \%$ of global capacity. It fell from
$40 \%$ during the last decade because of a strong growth of titanium sponge capacity in China. As seen in Fig. 3, output of CIS titanium sponge producers has notably increased during 2010-2012 in response to demands from both the aerospace and non-aerospace industries. Of the overall amount of $76.2 \mathrm{kT}$ in 2012, inputs of Russia, Kazakhstan and Ukraine in 2012 were 43.9, 22 and $10.3 \mathrm{kT}$, respectively. The CIS share in the global production of sponge remained stable in 2010-2012, slightly above $30 \%$ level. Up to $90 \%$ of the sponge produced by the VSMPO-AVISMA Corporation was being melted "in-house" to aerospace and industrial products while about half of the sponge produced by another Russian sponge producer, the recently opened Solikamsk Magnesium, was being exported. In Kazakhstan, Ust-Kamenogorsk Titanium and Magnesium Plant (UKTMP) lost its position as a leader in the supply of aerospace quality sponge to the USA in line with its strategy to expand ingot production. Respectively, most of UKTMP's sponge output was being melted domestically; only the remainder was being exported as aerospace grade sponge to USA, EU and Japan. In Ukraine, Zaporozhye Titanium and Magnesium Combine (ZTMC) was a supplier of the sponge mostly to single melt ingot and slab producers for the industrial market. A small volume of its sponge was being melt locally using its own Electron Beam Cold Hearth (EBCHM) furnace. Thus, by 2012, the CIS total sponge output overcompensated for the losses of the 2008-2009 crises; the same was true for every separate sponge producer. Forecasts for 2013-2014 looked optimistic for sponge producers. The biggest supply of titanium feedstock, ilmenite concentrate, for CIS sponge production comes from Ukraine, where main existing producers of titanium raw materials are located. The ilmenite concentrate can be estimated roughly as one-tenth of the global

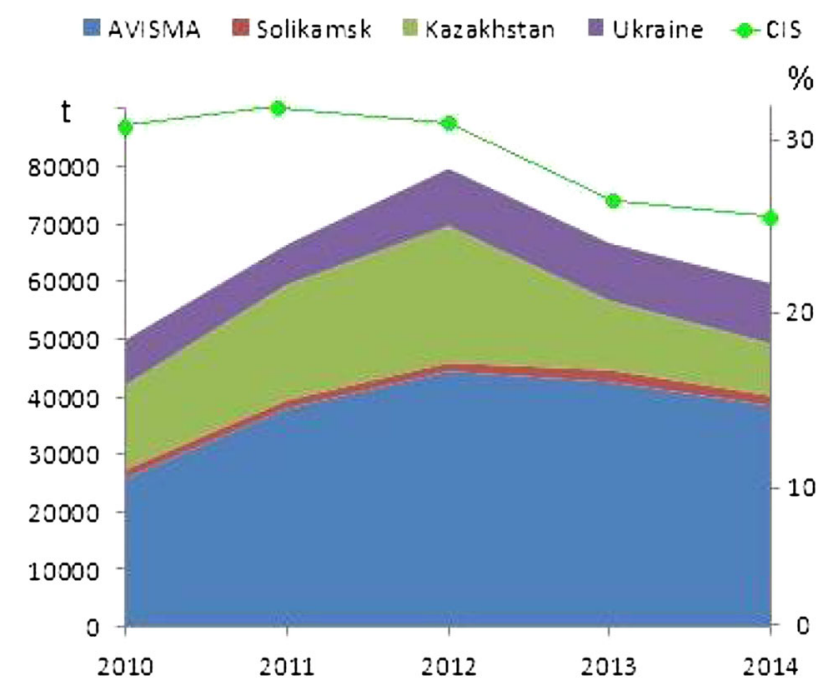

Fig. 3. Sponge production in CIS countries from 2010-2014 and their share to the global production. 
production. Rutile concentrate is being produced in Ukraine in the amount of around $70 \mathrm{kT}$ per year, mainly by the Volnogorsk mine. In the meantime, restructuring of the titanium industry in Ukraine is continuing. As one of their obligations, the "United Chemical Company" is going to develop new sources of titanium feedstock and to integrate enterprises related to the titanium metal and titanium pigment industry.

Production of bars and seamless titanium tubes was put into operation at JSC Chepetsk. Highquality seamless tubes are also being produced in Ukraine by JSC Oscar. Large-size spherical-shape forgings for marine applications are now being produced at JSC Uralkhimmash. The Megametal Company has become known as a producer of highquality titanium and titanium alloy bars. The Stupino Titanium Company is steadily increasing their titanium product assortment. The Admiral Company has entered the market as a producer of machined titanium parts. However, the VSMPOAVISMA Corporation is continuing to keep the leadership as the world's largest titanium producer. The product portfolio of the Corporation includes a full spectrum of products and services related to titanium manufacturing and treatment.

As the titanium market is growing dynamically worldwide, a vertically integrated CIS titanium industry is continuing to be an important part of the global network covering the entire supply chain, from titanium raw material to a wide range of titanium mill products. Several new manufacturers of titanium mill products have recently appeared on the CIS map. Impressive progress was achieved by JSC Ruspolimet (Kulebaki metallurgical plant) which is now capable of manufacturing a wide spectrum of forged and rolled products. The Company has a set of metallurgical facilities, including VAR and VIM, so that their forging and rolling facilities can work with their own ingots.

\section{DEVELOPMENTS IN TITANIUM RESEARCH AND APPLICATIONS IN GERMANY}

"Developments in Titanium Research and Applications in Germany" was authored by C. Siemers from Technische Universität Braunschweig and J. Kiese from VDM Metals $\mathrm{GmbH}$ and was presented by C. Siemers. Information is given on important achievements in the German titanium industry, governmental and non-governmental research organizations and universities since the Ti-2011 World Conference on Titanium. Research is mainly focused on the development of new alloys for aerospace and medical engineering. To reduce the production costs of conventional titanium alloys, advanced processes like electron beam melting or investment casting have been introduced into industrial production and rapid manufacturing, while multi-material design has been intensively investigated.
In Germany, titanium alloy production starts from titanium sponge which is imported mainly from America and Asia. VDM Metals GmbH is Germany's largest titanium producer. Besides several 4-metric-ton vacuum arc remelting furnaces (VAR), a new electron beam cold hearth remelting facility (EBCHR) equipped with six powerful electron guns has been installed, as shown in Fig. 4. Its capacity is approx. 5000 metric tons per year. During operation, titanium sponge, master alloys, individual alloying elements, as well as titanium scrap, compacts of chips and micro-components or a mixture of sponge and scrap, can be fed into the melt section. Typical products are blocks of rectangular shape with a length of more than $5 \mathrm{~m}$ as well as round bars with a weight of more than $12 \mathrm{t}$ which are afterwards thermo-mechanically processed. CP Titanium as well as alloys like $\mathrm{Ti} 6 \mathrm{Al} 4 \mathrm{~V}$ are mainly produced. In addition, the GfE Metalle and Materialien $\mathrm{GmbH}$ are producing master alloys, advanced titanium alloys and titanium aluminides in smaller quantities. Here, several VAR furnaces with capacitates up to $500 \mathrm{~kg}$, VAR skull melters and vacuum induction melting furnaces (VIM) up to 2 metric tons are being operated.

Semi-finished products, forgings and investment castings, as well as machined components of several alloys for the different industrial applications, are manufactured by, e.g., the Otto Fuchs KG, the Alcoa Power and Propulsion (the former TITAL GmbH Company), MTU Aero Engines AG and Rolls Royce Germany. Fundamental as well as applied research activities are carried out at German research organizations like the Fraunhofer IFAM, the Helmholtz Center Geesthacht or the German Aerospace Center (DLR) and several German and European universities.

New alloys have been developed, produced and introduced into industrial applications. Production costs of conventional titanium parts were reduced by the introduction of advanced processes like

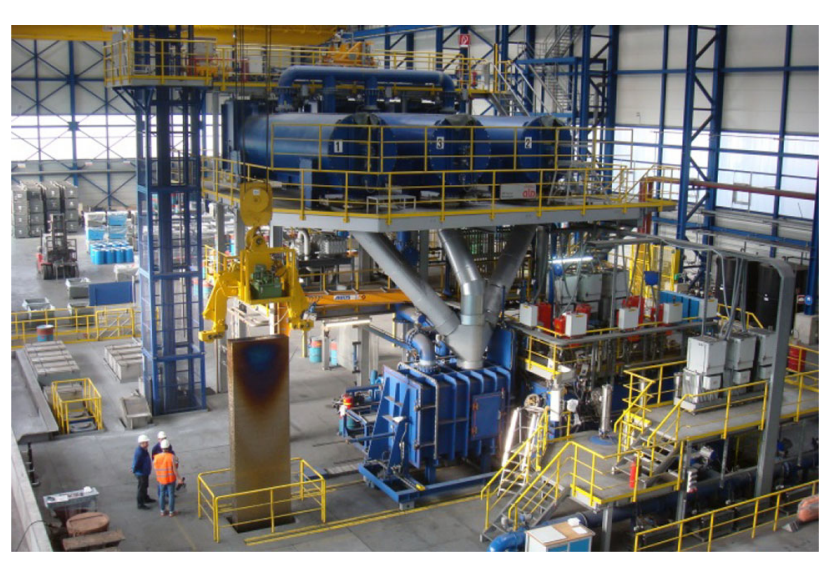

Fig. 4. Electron beam cold hearth remelting facility $(E B C H R)$ of VDM Metals $\mathrm{GmbH}$ installed in their production plant in Essen, Germany. 
electron beam melting and investment casting. Forgings of intermetallic $\gamma$-TiAl-based alloys allow its application in low-pressure turbine blades in the geared turbofan. Additive manufacturing, powder metallurgy, multi-material design and the feasibility of titanium scrap recycling have been investigated.

The German titanium community has continued to increase its output in leading-edge titanium research and technology, such as 3D screen printing of titanium and electrodeposition of titanium alloys from molten salt. Multidisciplinary research activities have been carried out by the German titanium industry, research organizations and higher education establishments. Collaborations are, in addition, being more and more expanded to European and international institutions.

\section{RECENT DEVELOPMENTS OF TITANIUM RESEARCH AND ENGINEERING ACTIVITIES IN FRANCE}

"Recent developments of titanium research and engineering activities in France" was authored and presented by Patrick Villechaise of Institute Pprime CNRS-ISAE/ENSMA-University of Poitiers. He reviewed activities in the production and forging of titanium, and in aeronautic and marine applications, including biomedical use and scientific research. He showed three new fields of activities dealing with forging, scraps and machining.

Due to increasing demand for titanium especially for aeronautic applications, different companies including ACB Aerospace Metals Solutions of France are active in meeting the challenges as shown in Fig. 5.
Aerospace is still a major driver for research and development, and it is anticipated that new programs at Airbus (A350 and A400M) will boost the titanium industry. With regard to aeroengines, important efforts and resources have been devoted to the development of predictive tools, from ingot melting to processing of final parts, including the challenge to develop aeroengines with an obvious reduction in fuel consumption. In most aeroengines, the blades are fixed mechanically onto the disk but linear friction welding (LFW), a 'solid state' joining process, is used for blades on a smaller disk. This reduces an estimated 'Buy to Fly' ratio from 30:1 to 6:1 as compared with a conventional machining operation. The reduction of the 'Buy to Fly' ratio is of great concern for economic reasons and several companies are involved in near-net shape technologies. Titanium is now considered as a key material in marine applications and an increased amount is being used in propulsion systems to manufacture seawater circuits. Biomedics is another field in which applications are still growing continuously and some examples were given. Numerous research programs are in progress in universities and public laboratories within the framework of national and international collaboration programs to investigate microstructure and texture evolution, thermomechanical processing/microstructure/mechanical properties relationships, process modeling and biomedical applications. Significant work is also being performed on welding and machining. No study is being carried out on the development of new conventional alloys, although there is a renewed interest in advanced TiAl alloys. Finally, the mission of the French Titanium Association, created in 1995 by a consortium of industries and

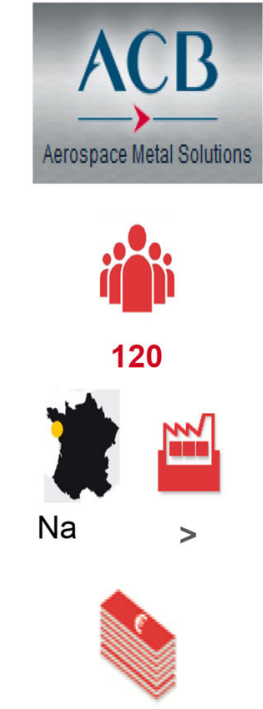

Forecast 2015

Turnover 45M€

\section{$\Rightarrow$ Hydraulic Presses Conception}
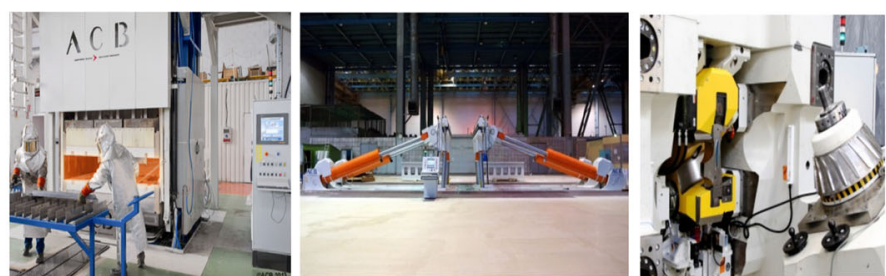

$\Rightarrow$ Titanium Parts Production:

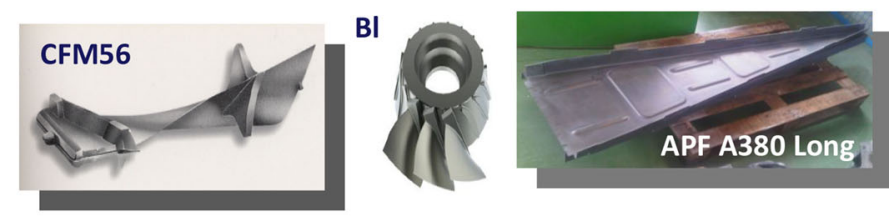

Titanium alloys: Ti6-Al-4V, Ti

Fig. 5. Companies involved in meeting the growing demand for titanium. 
institutions from the region of Nantes, France, was highlighted. This association offers a forum for the French titanium community, coming from industries, universities, research institutes and governmental agencies.

It was noted that there is no sponge plant and only limited smelting capacities in Europe, which are mainly located in UK, France, Germany and Italy. Within this context, the UKAD project between UKTMP (Ust-Kamenogorsk Titanium Magnesium Plant-Kazakhstan's titanium sponge producer) in Kazakhstan and Aubert \& Duval in Auvergne, France, is a very important industrial breakthrough. UKTMP's business is the mining of titanium ore and processing it into sponge. It is one of the main producers of titanium sponge in the world. Recently, UKTMP has invested in compaction and melting equipment in order to supply large titanium alloy ingots. Regarding Aubert \& Duval, a member of the ERAMET Group, the core activity of this company is developing, melting and hot-processing special steels, superalloys, aluminium alloys and titanium alloys. Aubert \& Duval provides advanced metallurgical solutions in the form of long products or parts required for projects in the most demanding industries including aerospace, energy, industrial tooling steels, medical and motor racing. The activity of UKAD will be the conversion of titanium ingots from UKTMP into long products, bars, wires, plates and sheets. It will rely on an automated short production cycle that uses the most advanced available technology.

\section{PROGRESS OF TITANIUM INDUSTRY, TECHNOLOGIES AND RESEARCH IN CHINA}

"Progress of Titanium Industry, Technologies and Research in China" was authored by Hui Chang from Nanjing Tech University and Lian Zhou from Northwest Institute for Nonferrous Metal Research and was presented by Hui Chang. Since the Ti-2011 conference held in Beijing, China, the shipments of mill products keep reducing and consumption is also showing the same trends. This has been due to the weak macroeconomy and the decrease of the speed of the development of Chinese GDP, but titanium research and development activities have still kept active. The highlights were mainly focused on the extraction technology development, new alloys development, the additive manufacturing process and powder metallurgies technologies as well as application technologies developments. The precise forging technologies and simulation as well as its applications were highlighted.

The changes of capacities and outputs of titanium sponge in China during the last 8 years are shown in Fig. 6. It can be seen that, during the past 4 years, the capacity and output of titanium sponge have made great improvements compared with 2007-2010, with an average increase of about $68 \%$, but the capacity and output of titanium sponge has continued to decrease in the last 4 years. This is mainly due to decreasing demand, especially in the chemical industry. By the end of 2014, a total of 12 titanium sponge manufacturers and 4 titanium manufacturers had been shut down since 2012.

In the past 4 years, titanium ingot capacity has been increased to more than 100,000 metric tons, which means that the ingot capacity is more than 2 times that of 2007. Figure 7 shows the changes of titanium ingot capacity and output in China during the last 8 years. It indicates that the titanium ingot capacity kept on increasing with nearly the same race of increase as in the years from 2007 to 2010 . By the end of 2014, the capacity of titanium ingots in China rose to more than 124,000 metric tons which is the top capacity in the Chinese titanium industry. However, the actual output of titanium ingots in China did not increase with the increase in capacity. The highest output of ingots was in 2012.

The actual output of titanium mill products has improved to a new stage during the past 4 years, with an output of more than 50,000 metric tons. Meanwhile, the consumption of titanium also reached a new level of more than 40,000 metric tons. Figure 8

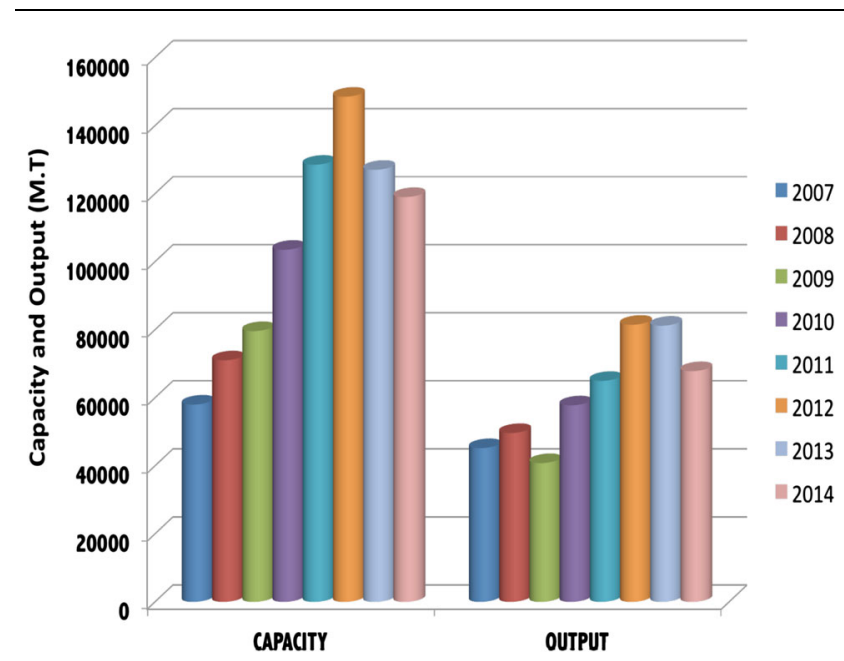

Fig. 6. Changes of capacity and output of sponge titanium in the last 8 years in China.

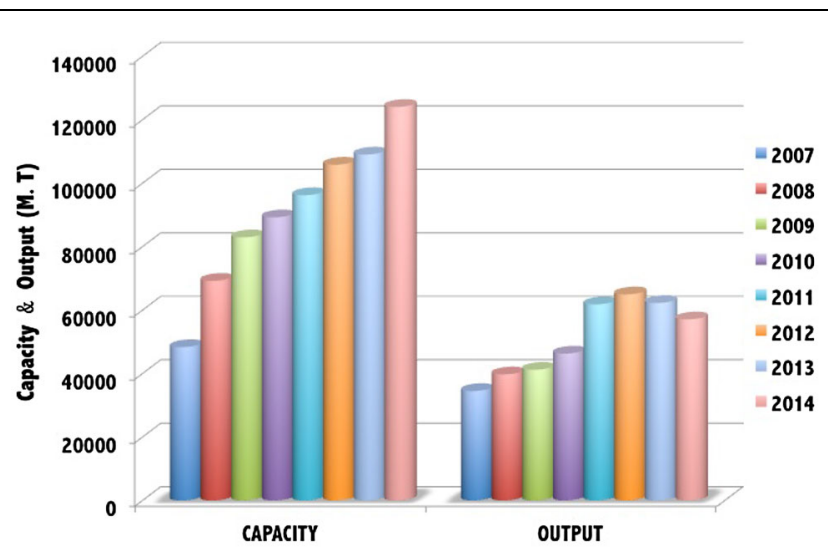

Fig. 7. Changes of capacity and outputs of titanium ingots in the past 8 years in China. 


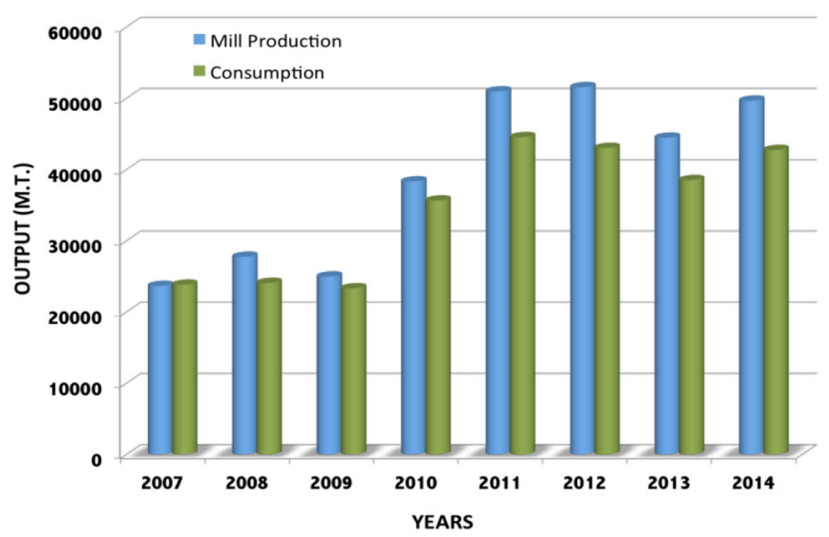

Fig. 8. Changes of output and consumption of titanium mill products of China in last 8 years.

shows the changes of outputs and consumptions of mill products of China in the last 8 years. This kind of situation will be mainly contributing to the decrease in the price of titanium sponge.

Concerning the consumption of the titanium mill products, Fig. 8 shows consumption changes of titanium products in China during the past 8 years. This indicates that the consumption amount of titanium products has increased by more than 10,000 metric tons compared with 2007-2009, and the total consumption amount has reached more than 40,000 metric tons in the past 4 years. Figure 9 shows the titanium products consumption structure of China at the end of 2014. This increased consumption of titanium products in China can be attributed to the increased demands of electric power, sports and leisure applications as well as marine applications.

It is interesting to note that the USTB process to fabricate titanium sponge and pure titanium metals is still very active in China. The USTB process relates to the molten-salt electrolysis method and was developed by Prof. Zhu of the University of Science and Technology, Beijing. During 2012, a pilot plant was set up by using the USTB process with an electrobath of $10,000 \mathrm{~A}$. The advantages of the USTB process are: (1) the titanium metal can be manufactured continuously with a short process; (2) a smaller intermediate product; (3) a simple carbothermal reduction reaction process with a high productivity, and (4) lower cost, low energy consumption and environmentally friendly. The most important aspect is that the cost of the USTB process is 60\% less compared to the traditional Kroll process.

It was noted that additive manufacturing technology is still very active, and remarkable progress has been made during the past 4 years in China. There are two important groups which are engaged in the additive manufacture technology: one is the Beihang University group and the other is Northwestern Polytechnical University (NPU). The Beihang group has successfully manufactured the largest part with a projected area of $5 \mathrm{~m}^{2}$ and a $3-$

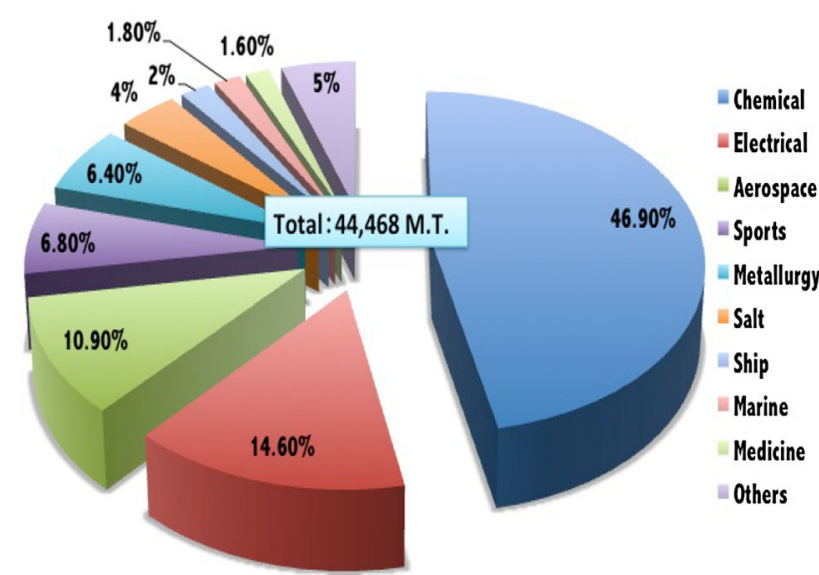

Fig. 9. Consumption structures of titanium mill products in China at the end of 2014.

m length part of titanium alloy for a C919 aircraft central flange. It has been manufactured by the NPU group.

In March 2014, a 3D printing cooperation project between Airbus and NPU was signed in Xi'an, indicating that $3 \mathrm{D}$ titanium parts will be qualified and applied in the Airbus aircraft in the future.

In summary, the Chinese titanium industry has met with a very difficult time. Overcapacity and a stagnant market still continue. The situation will remain until emerging applications can be found. However, the capacity and shipment of titanium sponge and mill products will continue to increase. The research on the fundamental science, engineering and technologies as well as applications will remain active, especially on ICME, additive manufacture technology, cost-efficient technology, nearnet forming technology and marine application technology.

\section{RECENT TOPICS OF TITANIUM RESEARCH AND DEVELOPMENT IN JAPAN}

"Recent Topics of Titanium Research and Development in Japan" was authored by Mitsuo Niinomi of Tohoku University and Kazuo Kagami of Toho Titanium Co. Ltd. and presented by Mitsuo Niinomi, who reviewed recent developments in a wide range of research and development of titanium in Japan.

The amounts of titanium sponge shipments in Japan (including estimated amount) are shown in Fig. 10 as a function of calendar year. The amount sharply decreased in 2009 because of the global economic crisis, but increased in 2012. However, the decrease in 2013 was because of the delay in the production of new commercial aircraft. This trend is similar to that of titanium sponge shipments throughout the world. In 2013, Japan was in third position for titanium sponge shipments in the world. The amounts of titanium mill products in Japan (including 


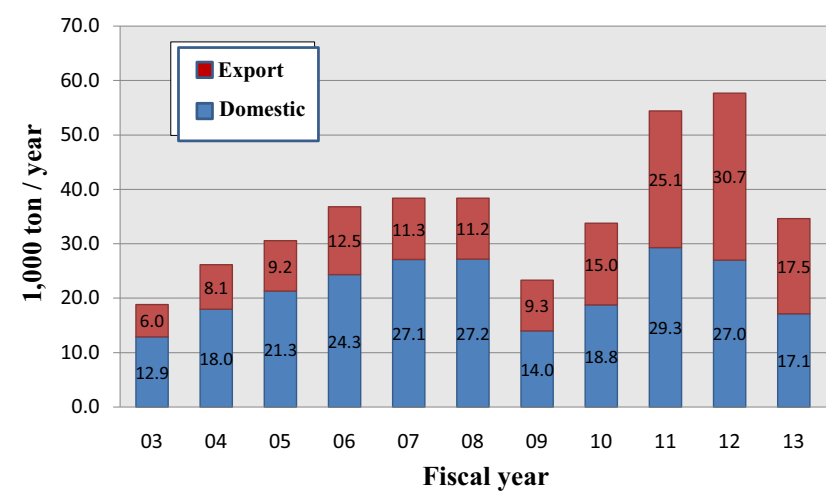

Fig. 10. Amount of titanium sponge in Japan as a function of calendar year, including estimated amount (courtesy of Japan Titanium Society).

estimated amount) are shown in Fig. 11 as a function of calendar year. Like the titanium sponge shipments, the amounts sharply decrease beginning in 2009, recover in 2011, and again decrease up to 2013. In 2014, they begin to increase again. In 2013, Japan was in fourth position for the production of Japanese titanium mill products in the world.

It was noted that, more recently, large national projects involving titanium structural materials have been instigated under industrial-academia-government cooperation. The project on the "Development of Advanced Titanium Alloy \& Production/Processing Technology for Next Generation Aircraft Structure" was started in 2008, and was renewed in 2013. This project is managed by the Sokeizai Center, Tokyo, Japan, and is supported by Ministry of Economy, Trade and Industry, Tokyo, Japan. The second stage of the project is from 2013 to 2016 and contains three major objectives concerning titanium alloys and one objective concerning magnesium alloys. The three objectives concerning titanium are as follows:

1. Joining methods of titanium alloys.

2. Powder metallurgy of titanium alloys.

3 . Non-destructive inspection.

Successful results of these objectives are expected after 3 years.

Another much larger project is the Innovative Structural Materials Project under the New Energy and Industrial Technology Development Organization (NEDO) supported by the Ministry of Economy, Trade and Industry, Tokyo, Japan. This project started in 2013. To carry out this project, the Innovative Structural Materials Association (ISMA) was established to control the project. The aim of the ISMA project is to reduce the weight of transportation equipment, primarily automobiles. The objectives of ISMA are as follows:

1. Development of joining technology.

2. Development of innovative steel sheet.

3. Development of non-ferrous metals.

4. Development of carbon fiber-reinforced thermo-

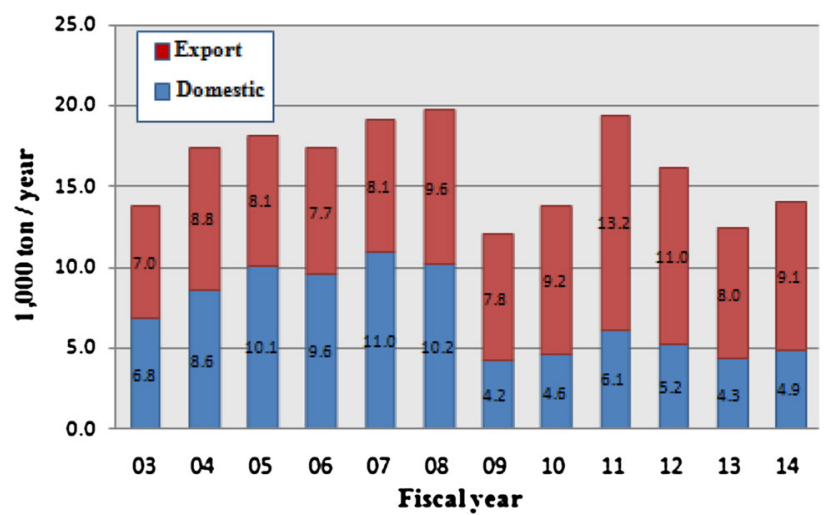

Fig. 11. Amount of Ti mill product in Japan as a function of calendar year; including estimated amount (courtesy of Japan Titanium Society).

plastics.

5. Strategic and basic research.

The non-ferrous metals in objective 3 includes aluminum, titanium, magnesium and carbon fiberreinforced plastics (CFRP). Objective 5 also includes the development of high-strength titanium alloys. Therefore, the ISMA project emphasizes research and development of titanium alloys for the structures of transportation equipment. The innovative development of titanium alloys with high strength and good ductility (workability) is already in progress. The innovative joining process of titanium alloys remains to be developed.

It was noted that the cross-ministerial Strategic Innovation Promotion program (SIP) is also a large project under the Japan Science and Technology Agency (JST) supported by the Cabinet Office of the Government of Japan. It began in 2014 and has ten objectives. One of them is the development of "structural materials for innovation". Under this objective, research and development of thermoplastics and FRP using thermoplastics, heat-resistant metallic materials such as high-temperature titanium alloys and Ni-based alloys, intermetallics such as TiAl and heatresistant ceramic coatings are being carried out. These integrated materials are being investigated using computational materials science and information engineering as well as conventional theory and experimental procedures. The final target of this objective is to apply innovative integrated materials to electric generators and aircraft.

Responding to a high demand for titanium in Japan, Japanese sponge titanium manufacturers have been strengthening and improving the productivity and cost. Despite the steep cost rise in titanium oxide raw material and electricity in Japan, Japanese sponge manufacturers have preceded the technical development by using low-grade titanium feedstock and a sponge batch size increase and improvement of efficiency, providing high-quality and cost-competitive titanium sponge all over the 
world. Japanese sponge titanium manufacturers have advanced technologies to produce high-purity titanium sponge and high-purity titanium. A large amount of the titanium produced in Japan is used for aviation applications due to its highly stable quality. Since eliminating defects such as low-density inclusions (LDI), an increase in aviation use is expected. The production process control and inspection systems are well established as of high quality and, therefore, the shipment for aviation applications accounts for a high percentage. Since Japanese sponge titanium manufacturers are capable of making high-purity titanium ( $5 \mathrm{~N}$ ), it fills the need for sputtering targets for semiconductors.

\section{CONCLUSION}

1. There were many excellent presentations from different countries which are being published by TMS as a conference proceedings. Since it is difficult to present highlights of all the presentations in this review, focus was given to the plenary talks from the organizing committee member countries.

2. The conference attracted participants from more than 25 countries as shown in Fig. 1. The total number of presentations exceeded 385 including more than 360 oral presentations and approximately 23 poster presentations.

3. Conference sessions were divided into the following topics: a. Extraction and Powder Production (3 sessions).

b. Wrought Processing and Fabrication (4 sessions).

c. Melting and Casting (2 sessions).

d. Alloy Composition-Microstructure-Properties (17 sessions).

e. Intermetallics and MMCs (3 sessions).

f. Additive and Near-Net Shape Manufacturing (4 sessions).

g. Environmental Behavior (2 sessions).

h. Aerospace Applications (3 sessions).

i. Biomedical and Healthcare Applications (3 sessions).

j. Industrial, Marine, and Other Applications (2 sessions).

k. ICME-Integrated Computational Materials Engineering (2 sessions).

4. Most of the sessions were well attended but sessions (f) and (k) seemed to be the most popular.

5. Looking ahead to the 14th WCT which will be held in Nantes, France in 2019, it will be interesting to continue to compare the activities in titanium in the world.

\section{ACKNOWLEDGEMENTS}

The author wishes to thank Trudi Dunlap, Programming Manager, The Minerals, Metals \& Materials Society for providing advance copies of plenary talks. 